\title{
A Cyanide-Based Coordination Polymer for Hydrogen Evolution Electrocatalysis
}

\author{
Elif Pınar Alsaç ${ }^{1}$ Emine Ulker ${ }^{2} \cdot$ Satya Vijaya Kumar Nune ${ }^{1} \cdot$ Ferdi Karadas $^{1,3}$ (D
}

Received: 27 September 2017 / Accepted: 6 December 2017 / Published online: 18 December 2017

(c) Springer Science+Business Media, LLC, part of Springer Nature 2017

\begin{abstract}
Research on $\mathrm{H}_{2}$ production has recently been directed to the development of cost-efficient and robust heterogeneous catalysts for hydrogen evolution reaction (HER). Given the promising catalytic activities of several cobalt-based systems and the robustness of Prussian blue analogues in harsh catalytic processes including water oxidation, a Co-Co Prussian blue analogue was investigated as a HER catalyst for the first time. Co-Co Prussian Blue modified fluorine doped tin oxide (FTO) electrode demonstrated a significant HER activity with an onset overpotential of $257 \mathrm{mV}$, a Tafel slope of $80 \mathrm{mV} \mathrm{dec}^{-1}$, and a turnover frequency of $0.090 \mathrm{~s}^{-1}$ at an overpotential of $250 \mathrm{mV}$. Comparative XPS, Infrared, and XRD studies performed on pristine and post-catalytic electrodes confirm the stability of the catalyst.
\end{abstract}

\section{Graphical Abstract}

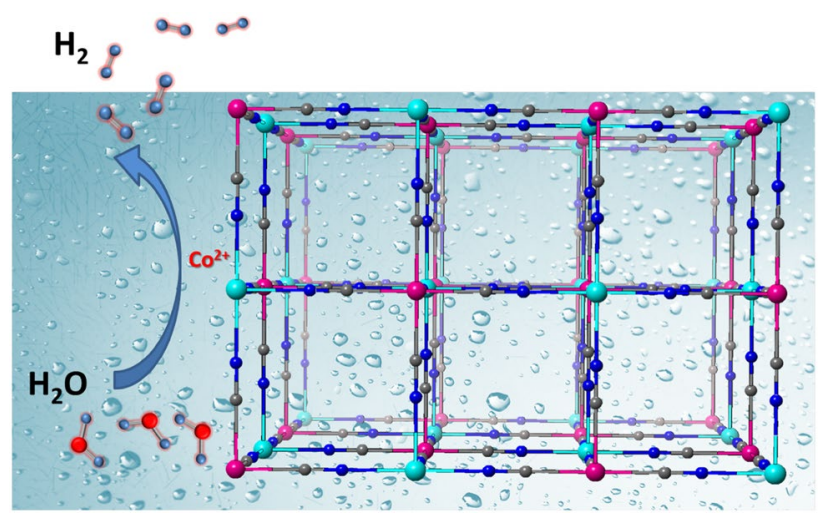

Keywords Prussian blue $\cdot$ Cyanide $\cdot$ Water reduction $\cdot$ Hydrogen evolution $\cdot$ Electrocatalysis

Electronic supplementary material The online version of this article (https://doi.org/10.1007/s10562-017-2271-6) contains supplementary material, which is available to authorized users.

Ferdi Karadas

karadas@fen.bilkent.edu.tr

1 Department of Chemistry, Bilkent University, 06800 Ankara, Turkey

2 Department of Chemistry, Faculty of Arts \& Sciences, Recep Tayyip Erdogan University, 53100 Rize, Turkey

3 UNAM-Institute of Materials Science and Nanotechnology, Bilkent University, 06800 Ankara, Turkey

\section{Introduction}

Exponential increase in global energy demand and adverse climatic changes triggered by extensive usage of carbonbased fossil fuels stress the importance of clean and sustainable alternative energy sources [1-3]. Hydrogen, with a high energy density, appears to be a promising energy carrier without any harmful by-products $[4,5]$. Production of hydrogen from water, however, has emerged to be a significant challenge due to lack of efficient and costfriendly water reduction catalysts [6-10]. $\mathrm{H}_{2}$ production with electrochemical and photochemical water reduction has 
attained considerable attention over past few decades [11, 12]. Although platinum and iridium based materials were reported to show efficient catalytic activity in reducing water at relatively low overpotentials, being precious metals and low abundance limit their application in bulk $\mathrm{H}_{2}$ production [13-15]. Hence, the main focus in this field has currently been given to the development of water reduction catalysts incorporating abundantly-available first row transition metal ions [16-19]. Much emphasis has been given to cobalt containing compounds as catalysts for hydrogen evolution reaction (HER) over the past decade for their versatile redox chemistry, ease in preparation, and robustness [20-24]. The investigation of a molecular pentapyridyl cobalt complex as a HER catalyst in water buffered at $\mathrm{pH} 7$ exhibits an onset overpotential of $660 \mathrm{mV}$ at Faradaic efficiency close to $100 \%$ with carbon-free by-products [25]. Cobo et al. reported the investigation of cobalt-based catalytic material $\left(\mathrm{H}_{2}\right.$-Cocat) for electrocatalytic reduction of water at $\mathrm{pH} 7$, exhibiting catalytic onset overpotential of $50 \mathrm{mV}$ with $100 \%$ Faradaic efficiency [26]. Similar investigation by Sun et al. studying electrodeposited cobalt-sulfide catalyst for electrochemical and photochemical $\mathrm{H}_{2}$ generation from water reported a low catalytic onset overpotential of only $43 \mathrm{mV}$ and near $100 \%$ Faradaic efficiency in phosphate buffer at pH 7 [27]. Moreover, Khnayzer et al. performed a comprehensive investigation of visible-light photo-generation of $\mathrm{H}_{2}$ from water using cobalt(II) polypyridyl complexes as catalysts, $\left[\mathrm{Ru}(\mathrm{bpy})_{3}\right]^{2+}$ as a photosensitizer (PS), and ascorbic acid/ascorbate as an electron source, achieving a turnover number (TON) of 4200 $\left(\mathrm{H}_{2} / \mathrm{Co}\right)$ and a turnover frequency (TOF) of $3200\left(\mathrm{H}_{2} / \mathrm{Co}\right.$ per h) under simulated sunlight at $\mathrm{pH} 4$ [28].

Prussian Blue analogues (PBAs) with cubic structured $\mathrm{M}\left[\mathrm{M}^{\prime}(\mathrm{CN})_{6}\right]$ framework have recently been investigated to address critical steps of hydrogen economy including $\mathrm{H}_{2}$ storage and water oxidation $[29,30]$. The relatively high stability of this family of coordination compounds over a wide range of $\mathrm{pH}$ and easy synthesis together with their porous nature and the availability of electroactive metal sites make them promising candidates for various applications ranging from selective gas adsorption to catalysis. Several studies focusing on the water-oxidation performance of PBAs clearly show that cobalt sites on the surface could be used for water oxidation process and that cyanide based coordination compounds can retain their three-dimensional structure even under harsh catalytic conditions [31,32].

A Prussian blue analogue, $\mathrm{K}_{4} \mathrm{Fe}_{4}\left[\mathrm{Fe}(\mathrm{CN})_{6}\right]_{3}$, has also been investigated as a water reduction catalyst in 1997 with a low catalytic activity [33], and hence no in-detailed studies have been carried-out further on other PBAs. Taking into consideration the efficiency of cobalt-based water-reduction catalysts, and no apparent investigations reporting the application of PBA derivatives in water-reduction, the current article aims to re-evaluate the application of a Prussian Blue analogue, cobalt hexacyanocobaltate, as a HER catalyst. Metal hexacyanocobaltates incorporating $\mathrm{Co}$ and $\mathrm{Zn}$ ions were synthesized by previously reported methods $[34,35]$.

\section{Experimental}

\subsection{Materials}

All of the reagents were procured from Sigma-Aldrich and used without any further processing; $\mathrm{Co}\left(\mathrm{NO}_{3}\right) \cdot 6 \mathrm{H}_{2} \mathrm{O}$ (99.99\%), $\mathrm{Zn}\left(\mathrm{NO}_{3}\right)_{2} \cdot 6 \mathrm{H}_{2} \mathrm{O}(98 \%), \mathrm{K}_{3} \mathrm{Co}(\mathrm{CN})_{6}(\geq 97.0 \%)$. All solutions were prepared with Millipore deionized water with the resistivity of $18.2 \mathrm{~m} \Omega \mathrm{cm}$.

\subsection{Bulk Catalyst Preparation}

$0.2 \mathrm{M} 25 \mathrm{ml}$ solutions of $\mathrm{Co}\left(\mathrm{NO}_{3}\right)_{2} \cdot 6 \mathrm{H}_{2} \mathrm{O}$ and $\mathrm{K}_{3} \mathrm{Co}(\mathrm{CN})_{6}$ in water were prepared separately at room temperature. $\mathrm{Co}$ (II) solution was added drop wise to $\left[\mathrm{Co}(\mathrm{CN})_{6}\right]^{3-}$ solution. The reaction mixture was left under stirring for $1 \mathrm{~h}$ and then aged overnight. The precipitate was filtrated under suction and stored in a desiccator. The resulting powder was pink in colour. Same procedure was applied to $\mathrm{Zn}-\mathrm{Co}$ PBA. The starting materials were the solutions of $0.2 \mathrm{M} \mathrm{Zn}\left(\mathrm{NO}_{3}\right)_{2} \cdot 6 \mathrm{H}_{2} \mathrm{O}$ and $\mathrm{K}_{3} \mathrm{Co}(\mathrm{CN})_{6}$. The colour of powder $\mathrm{Zn}-\mathrm{Co} \mathrm{PB}$ is white.

\subsection{Material Characterization}

FTIR spectra of bulk Co-Co and Zn-Co PBA were measured using Bruker ALPHA Platinum-ATR spectrometer in the wave number range $4000-400 \mathrm{~cm}^{-1}$. Powder X-ray diffraction (XRD) patterns were recorded by Panalytical X'PertPro Multipurpose X-Ray Diffractometer (MPD) employing $\mathrm{Cu} \mathrm{K} \alpha \mathrm{X}$-ray radiation $(\lambda=1.5418 \AA$ ). Energydispersive $\mathrm{X}$-ray spectroscopy (EDX) analysis was carried out at $30 \mathrm{kV}$ using FEI-Quanta 200 FEG ESEM. Thin film $\mathrm{X}$-ray diffraction (GI-XRD) patterns of $\mathrm{Co}-\mathrm{Co}$ and $\mathrm{Zn}-\mathrm{Co}$ PBA coated fluorine doped tin oxide coated glass (FTO) electrodes were recorded by Panalytical X'Pert3 MRD Material Research Diffractometer (MRD) employing $\mathrm{Cu} \mathrm{K} \alpha$ $\mathrm{X}$-ray radiation $(\lambda=1.5418 \AA$ ) at an incident (w) angle of $0.5^{\circ}$. X-ray photoelectron spectroscopy (XPS) studies were performed using Thermo Scientific K-Alpha X-Ray Photoelectron Spectrometer system operating with $\mathrm{Al} \mathrm{K} \alpha$ microfocused monochromator source (hv-1486.6 eV and $400 \mathrm{~mm}$ spot size) along with a flood gun for charge neutralization, pass energy $200 \mathrm{eV}$ was used for survey scan and $30 \mathrm{eV}$ individual element scans. Origin Pro 8.5 was used to plot and analyze all the graphs. 


\subsection{Catalyst Modified FTO Electrodes}

FTO electrodes $\left(1 \times 2 \mathrm{~cm}, 2 \mathrm{~mm}\right.$ with $7 \Omega \mathrm{sq}^{-1}$ surface resistivity and $\sim 80 \%$ transmittance) were washed by sonication for $10 \mathrm{~min}$ in basic soapy solution, deionized water and isopropanol, followed by annealing at $400{ }^{\circ} \mathrm{C}$ for $30 \mathrm{~min}$. A two-step in-situ method was used to prepare the electrodes, which includes spin coating the hexacyanocobaltate precursor onto the FTO surface followed by dipping it in a cobalt, or zinc solution. Solutions of $0.2 \mathrm{M} \mathrm{Co}\left(\mathrm{NO}_{3}\right)_{2} \cdot 6 \mathrm{H}_{2} \mathrm{O}$ and $0.2 \mathrm{M} \mathrm{K}_{3}\left[\mathrm{Co}(\mathrm{CN})_{6}\right]$ were prepared with Millipore water. $\mathrm{K}_{3}\left[\mathrm{Co}(\mathrm{CN})_{6}\right]$ solution was spin-coated onto FTO electrodes at $1500 \mathrm{rpm}$ for $3 \mathrm{~min}$, after that, the electrodes were immersed in a solution of $\mathrm{Co}\left(\mathrm{NO}_{3}\right)_{2} \cdot 6 \mathrm{H}_{2} \mathrm{O}$ for $5 \mathrm{~min}$. Both steps were repeated three times. The electrodes were kept in a vacuum desiccator until further use. The electrodes were rinsed with deionized water prior to use. Similar coatings were made onto FTO electrodes (at $1500 \mathrm{rpm}$ for $3 \mathrm{~min}$ ) using solutions of $0.2 \mathrm{M} \mathrm{Zn}\left(\mathrm{NO}_{3}\right)_{2} \cdot 6 \mathrm{H}_{2} \mathrm{O}, 0.2 \mathrm{M}$ $\mathrm{K}_{3}\left[\mathrm{Co}(\mathrm{CN})_{6}\right]$, and $0.2 \mathrm{M} \mathrm{Co}\left(\mathrm{NO}_{3}\right)_{2} \cdot 6 \mathrm{H}_{2} \mathrm{O}$.

\subsection{Electrochemical Studies}

Electrochemical studies were performed at room temperature under inert conditions $\left(\mathrm{N}_{2}\right.$ atmosphere) using Gamry Instruments Interface 1000 Potentiostat/Galvanostat. A conventional three-electrode electrochemical cell with $\mathrm{Ag} /$ $\mathrm{AgCl}(3.5 \mathrm{M} \mathrm{KCl})$ as a reference electrode, $\mathrm{Pt}$ wire as a counter electrode, and FTO as a working electrode were used. All potentials were measured versus $\mathrm{Ag} / \mathrm{AgCl}$ reference electrode and were reported versus the normal hydrogen electrode (NHE) using the equation of $\mathrm{E}(\mathrm{NHE})=\mathrm{E}(\mathrm{Ag} /$ $\mathrm{AgCl})+0.205 \mathrm{~V}$. Linear sweep voltammetry (LSV) measurements of Co-Co PBA modified FTO electrode (denoted as $\left[\mathrm{CoCo}(\mathrm{CN})_{6} @ \mathrm{FTO}\right]$ throughout the manuscript $), \mathrm{Zn}-\mathrm{Co}$ PBA modified FTO electrode (denoted as $\left[\mathrm{ZnCo}(\mathrm{CN})_{6} @\right.$ FTO] throughout the manuscript), and bare FTO were recorded in $50 \mathrm{mM} \mathrm{KPi} \mathrm{(pH} \mathrm{7.0)} \mathrm{containing} 1 \mathrm{M} \mathrm{KNO}_{3}$ as electrolyte between 0 and $-1 \mathrm{~V}$ (vs NHE) with a scan rate of $5 \mathrm{mV} \mathrm{s}^{-1}$. Neutral phosphate buffer solution was prepared using $\mathrm{K}_{2} \mathrm{HPO}_{4}$ and $\mathrm{KH}_{2} \mathrm{PO}_{4}(\mathrm{KPi})$ while $\mathrm{H}_{3} \mathrm{PO}_{4}$ and $\mathrm{KOH}$ were used to regulate $\mathrm{pH}$. Prior to the studies, the electrodes were dipped into the buffer solution and the solution was purged with $\mathrm{N}_{2}$ gas for 15 min to remove dissolved $\mathrm{O}_{2}$. The gas generated during the electrolysis was analyzed with an Agilent 7820A gas chromatograph equipped with a Molesieve GC column $(30 \mathrm{~m} \times 0.53 \mathrm{~mm} \times 25 \mu \mathrm{m})$ thermostated at $40{ }^{\circ} \mathrm{C}$ and a TCD detector thermostated at $100{ }^{\circ} \mathrm{C}$ to detect hydrogen $\left(\mathrm{H}_{2}\right)$. Argon was used as the carrier gas. To avoid cross contamination, the electrochemical cell was purged with nitrogen for $20 \mathrm{~min}$ prior to the experiment. $100 \mu \mathrm{L}$ aliquots of gas were collected from the headspace of the electrochemical cell over 10-min intervals with a gas-tight Hamilton syringe. The retention time of hydrogen was recorded as $0.77 \mathrm{~min}$.

\section{Results and Discussion}

\subsection{Material Characterization}

Infrared studies performed on the as synthesized Co-Co PBA reveal strong bands at 2169,444 , and $1607 \mathrm{~cm}^{-1}$ corresponding to the vibrational stretches $v(\mathrm{CN}), \mathrm{v}\left(\mathrm{Co}^{\mathrm{II}}-\mathrm{NC}-\mathrm{Co}^{\mathrm{III}}\right)$, and bending stretch $v(\mathrm{H}-\mathrm{O}-\mathrm{H})$, respectively (Fig. 1). Similarly, ATR spectrum of $\mathrm{Zn}-\mathrm{Co}$ PBA reveals strong bands at 2171,440 , and $1609 \mathrm{~cm}^{-1}$ corresponding to the vibrational stretches $v(\mathrm{CN}), v\left(\mathrm{Zn}^{\mathrm{II}}-\mathrm{NC}-\mathrm{Co}^{\mathrm{III}}\right)$, and bending stretch $v(\mathrm{H}-\mathrm{O}-\mathrm{H})$, respectively (Fig. 1). Zinc to cobalt ratio in $\mathrm{Zn}-\mathrm{Co}$ PBA was confirmed to be 1.6:1 by EDX. The powder X-ray diffraction patterns (Supporting Fig. S1) of Co-Co and $\mathrm{Zn}-\mathrm{Co}$ PBA crystallites correspond well with the previously reported PBAs. All the peaks indexed by comparing to the reported PBAs confirm face-centered cubic unit cell assuming a $F m 3 m$ space group $[34,36]$.

\subsection{Electrochemical Studies}

Figure 2 shows Linear sweep voltammetry (LSV) curves of $\left[\mathrm{ZnCo}(\mathrm{CN})_{6} @ \mathrm{FTO}\right]$ and $\left[\mathrm{CoCo}(\mathrm{CN})_{6} @ \mathrm{FTO}\right]$. As seen Fig. 2, [CoCo(CN) $)_{6}$ FTO] exhibits a significant HER activity with an onset overpotential of $257 \mathrm{mV}$, which is extracted from Tafel plot. A non-unique way to determine the onset overpotential was employed where the beginning of linear regime in the Tafel plot with low current densities is used [37]. LSV of [ $\left.\mathrm{ZnCo}(\mathrm{CN})_{6} @ \mathrm{FTO}\right]$ and that of bare electrode are identical indicating that the origin of HER activity in

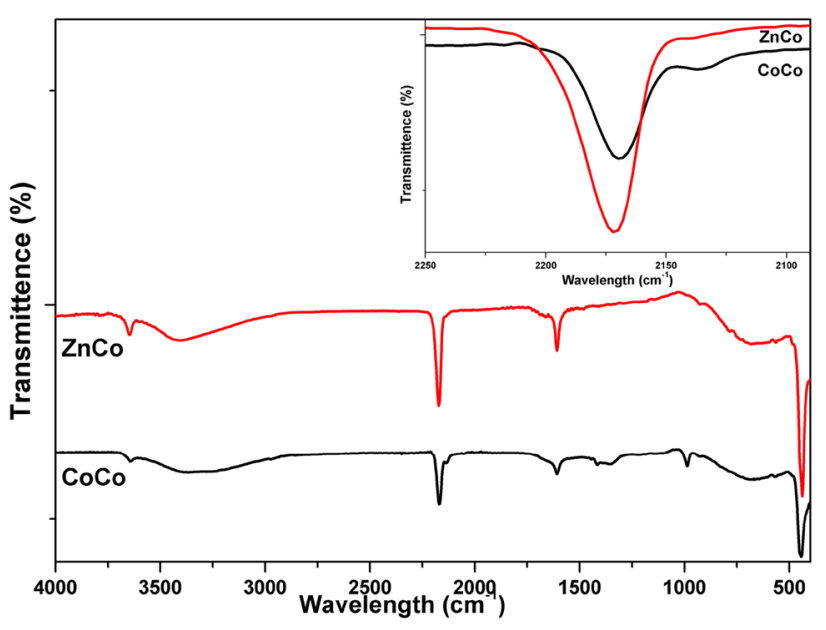

Fig. 1 FTIR spectra of bulk Co-Co (black) and Zn-Co (red) PBA. Inset: $v(\mathrm{CN})$ stretches of $\mathrm{Co}-\mathrm{Co}$ and $\mathrm{Zn}-\mathrm{Co}$ PBA 


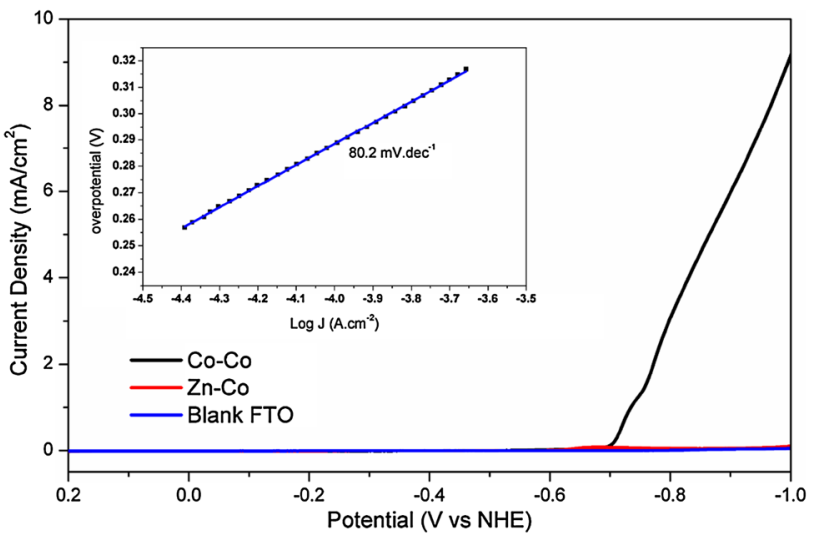

Fig. 2 LSV curves of $\left[\mathrm{CoCo}(\mathrm{CN})_{6} @ \mathrm{FTO}\right]$ (black), $\left[\mathrm{ZnCo}(\mathrm{CN})_{6} @\right.$ FTO] (red), and blank FTO (blue) electrodes recorded in a $50 \mathrm{mM}$ $\mathrm{KPi}$ buffer solution with $1 \mathrm{M} \mathrm{KNO}_{3}$ as electrolyte at $\mathrm{pH} 7.0$ with a sweep rate of $5 \mathrm{mV} \mathrm{s}^{-1}$. Inset: Tafel plot for [CoCo $\left.(\mathrm{CN})_{6} @ \mathrm{FTO}\right]$ derived from the LSV curve (black line) and linear fitting curve (blue dotted) rendering a Tafel slope of $80.2 \mathrm{mV} \mathrm{dec}^{-1}$

$\left[\mathrm{CoCo}(\mathrm{CN})_{6} @ \mathrm{FTO}\right]$ is only due to $\mathrm{Co}^{\mathrm{II}}$ sites surrounded with nitrogen atoms $\left(\mathrm{CoN}_{6}\right)$ of nitrile group and that $\mathrm{Co}^{\mathrm{III}}$ centers in hexacyanocobaltate units do not participate in catalytic water reduction process.

Tafel plot of the catalyst, which was obtained from the LSV curve of $\left[\mathrm{CoCo}(\mathrm{CN})_{6} @ \mathrm{FTO}\right]$ at a scan rate of $5 \mathrm{mV} \mathrm{sec}^{-1}$, was used to extract two important electrochemical parameters; (i) Tafel slope (b) and (ii) exchange current density $\left(\mathrm{i}_{0}\right)$. Tafel slope, as shown in Fig. 2 Inset, was used for the specification of the overpotential required to raise the current density by one order of magnitude [38] and the prediction of mechanism for catalytic process. Tafel slope determined as $80 \mathrm{mV} \mathrm{dec}{ }^{-1}$, was similar to the reported values for cobalt-sulfide film (Co-S/FTO) $\left(93 \mathrm{mV} \mathrm{dec}^{-1}\right)$ [27], and Co-P/CC NWs array $\left(93 \mathrm{mV} \mathrm{dec}^{-1}\right)$ [31]. This value was also found to be slightly higher than the ones reported for FeP/CC $\left(70 \mathrm{mV} \mathrm{dec}{ }^{-1}\right)$ [39], $\mathrm{Ni}_{0.33} \mathrm{Co}_{0.67} \mathrm{~S}_{2}$ $\left(67.8 \mathrm{mV} \mathrm{dec}{ }^{-1}\right)$ [40], Co-P/Ti $\left(58 \mathrm{mV} \mathrm{dec}^{-1}\right)$ [41], and Co-30Ni-B $\left(51 \mathrm{mV} \mathrm{dec}^{-1}\right)$ [38] at neutral conditions. From the Tafel plot a 2 step mechanism for HER was predicted to be initiated by proton discharge step (Volmer step, $120 \mathrm{mV} \mathrm{dec}^{-1}$ ) followed by electrochemical desorption (Heyrovsky step, $40 \mathrm{mV} \mathrm{dec}^{-1}$ ) or chemical desorption (Tafel step, $30 \mathrm{mV} \mathrm{dec}^{-1}$ ) [38, 42, 43]. HER involves a multistep reaction process, which can proceed with two possible mechanisms: Volmer-Tafel or Volmer-Heyrovsky. The initial step, proton discharge to form adsorbed $\mathrm{H}$ (Volmer step, $120 \mathrm{mV} \mathrm{dec}^{-1}$ ), is the same for both mechanisms. It is then followed by either electrochemical desorption (Heyrovsky step, $40 \mathrm{mV} \mathrm{dec}^{-1}$ ) or chemical desorption to form $\mathrm{H}_{2}$ (Tafel step, $30 \mathrm{mV} \mathrm{dec}^{-1}$ ) [44]. Since the latter mechanism requires two close $\mathrm{H}$-atom adsorption sites, the Volmer-Tafel $\mathrm{H}$ recombination pathway is rare as an HER mechanism,

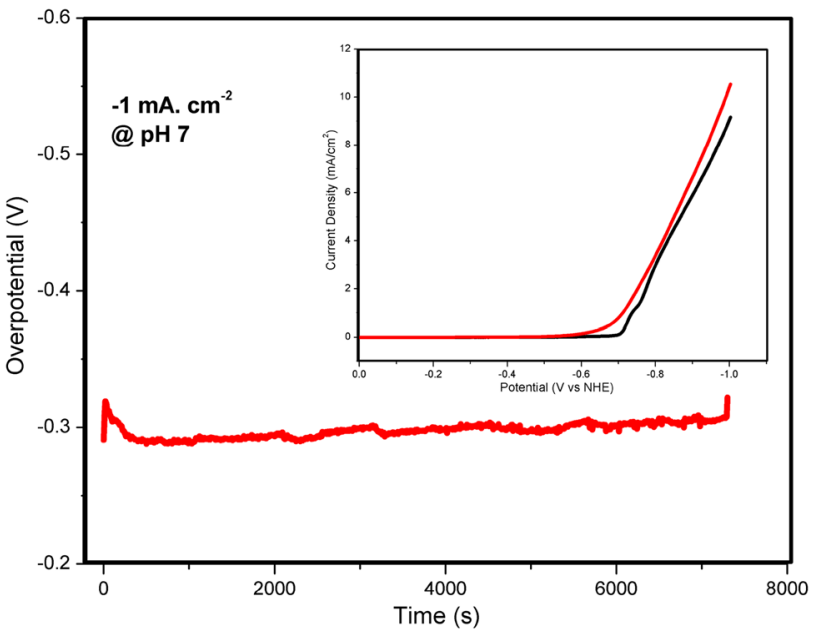

Fig. 3 Chronopotentiometry curve obtained for $\left[\mathrm{CoCo}(\mathrm{CN})_{6} @ \mathrm{FTO}\right]$ at $\mathrm{pH} 7$ and $1 \mathrm{~mA} \mathrm{~cm}{ }^{-2}$. Inset shows the LSV comparison between the pristine (black) and post-catalytic (red) electrodes with a scan rate $5 \mathrm{mV} \mathrm{s}^{-1}$

except at active Pt [45]. Considering that cobalt sites in PB structure are well separated from each other $(\sim 10 \AA)$ Volmer Heyrovsky pathway should be the mechanism. A Tafel slope of $80 \mathrm{mV} \mathrm{dec}^{-1}$ for $\left[\mathrm{CoCo}(\mathrm{CN})_{6} @ \mathrm{FTO}\right]$ is also in line with a Volmer-Heyrovsky reaction mechanism [38, 42, 43].

Exchange current density $\left(\mathrm{j}_{0}\right)$ could also be determined at an overpotential of $0 \mathrm{~V}$ from Tafel analysis. The exchange current density for $\left[\mathrm{CoCo}(\mathrm{CN})_{6} @ \mathrm{FTO}\right]$ in $\mathrm{pH} 7$ was calculated to be $2.55 \times 10^{-8} \mathrm{~A} \mathrm{~cm}^{-2}$, which was similar with $2 \times 10^{-8} \mathrm{~A} \mathrm{~cm}^{-2}$ geom for electropolymerized $\mathrm{Co}(\mathrm{II})$ dibenzotetraaza(14) annulene system (CoTAA) [16], $5.9 \times 10^{-8} \mathrm{~A} \mathrm{~cm}^{-2}$ for $\mathrm{CoSe}_{2}$ films [46], and $8.2 \times 10^{-8} \mathrm{~A} \mathrm{~cm}^{-2}$ for $\mathrm{MoO}_{3}-\mathrm{MoS}_{2} /$ FTO electrode [47]. Since the stability of the catalyst is essential particularly for practical applications, chronopotentiometry measurement was performed for $\left[\mathrm{CoCo}(\mathrm{CN})_{6} @ \mathrm{FTO}\right]$ at a constant current density of $1 \mathrm{~mA} \mathrm{~cm}{ }^{-2}$ for $2 \mathrm{~h}$. The performance of $\left[\mathrm{CoCo}(\mathrm{CN})_{6} @ \mathrm{FTO}\right]$ for hydrogen evolution showed very good durability for two hours with an overpotential of $295 \mathrm{mV}$. No significant increase of the overpotential under this condition was observed, suggesting the stability of the catalyst throughout the experiment as shown in Fig. 3. Furthermore, the similarity of LSV curve of the pristine catalyst and that of the catalyst after $2 \mathrm{~h}$ of chronopotentiometry experiment supports the claim on the superior stability of the modified electrode, as shown in Fig. 3 inset.

Figure 4 displays charge accumulated over time in a controlled potential electrolysis at $-0.8 \mathrm{~V}$ (vs. NHE) in the absence and presence of $\mathrm{Co}-\mathrm{Co}$ PBA on FTO electrode in $50 \mathrm{mM}$ KPi buffer solution with $1 \mathrm{M} \mathrm{KNO}_{3}$ as an electrolyte at $\mathrm{pH}$ 7.0. The catalyst affords a robust and essentially linear charge build-up over time with no significant loss in 

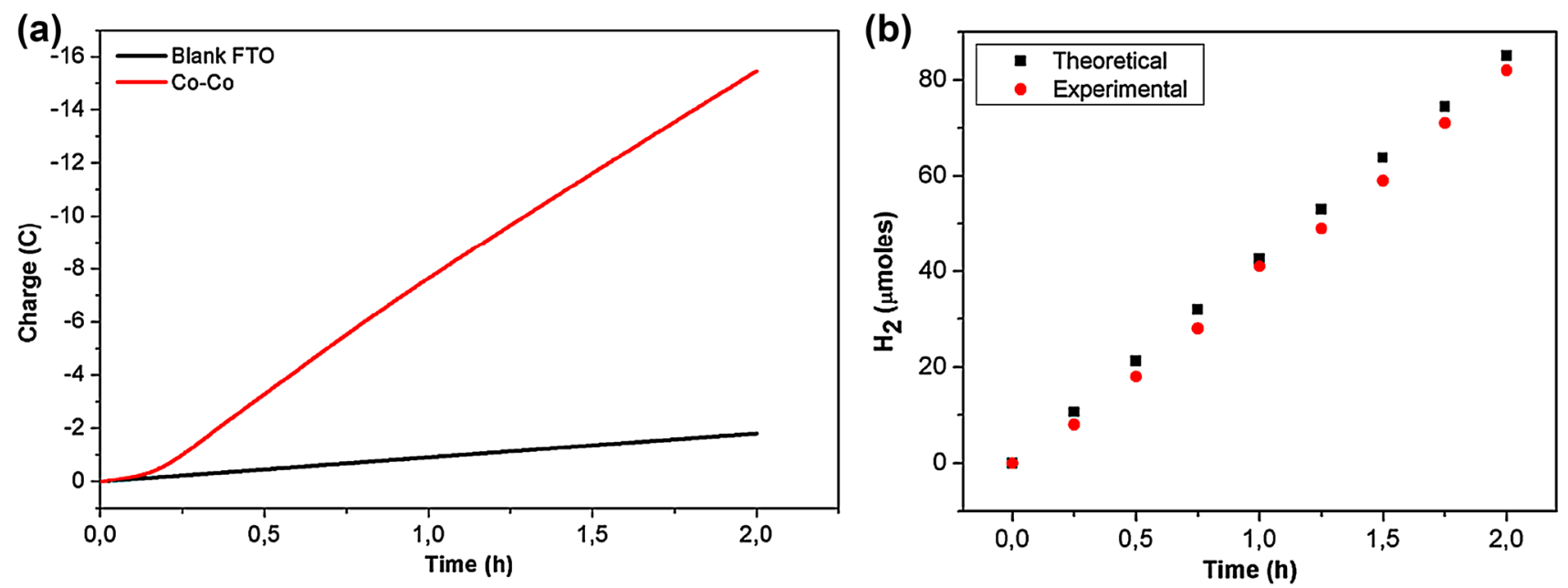

Fig. 4 a Charge accumulated over time in a controlled potential electrolysis at $-0.8 \mathrm{~V}$ versus NHE in the absence (black line) and presence of Co-Co PBA on FTO electrode (red line) in $50 \mathrm{mM} \mathrm{KPi}$ buffer solution with $1 \mathrm{M} \mathrm{KNO}_{3}$ as electrolyte at $\mathrm{pH}$ 7.0. (b) $\mathrm{H}_{2}$ pro-

activity over the course of at least $2 \mathrm{~h}$. In contrast, negligible charge was passed when a blank FTO electrode was used as the working electrode under the same conditions. Cyclic voltammogram (CV) at different scan rates was recorded in the range of $0.7-1.2 \mathrm{~V}$ versus NHE to determine the coverage of redox-active Co centers on the electrode (Supporting Fig. S2). The surface concentration, calculated to be $2.0 \mathrm{nmol} \mathrm{cm}{ }^{-2}$, was used to determine the turnover frequency (TOF) for $\left[\mathrm{CoCo}(\mathrm{CN})_{6} @ \mathrm{FTO}\right]$. A TOF value of $0.090 \mathrm{~s}^{-1}$ was calculated from Tafel plot at an overpotential of $250 \mathrm{mV}$, which is higher than that reported for Co-cat $\left(0.022 \mathrm{~s}^{-1}\right.$ at $\left.385 \mathrm{mV}\right)$ [26] and Co-S film $\left(0.017 \mathrm{~s}^{-1}\right)$ [27] at $\mathrm{pH}$ 7.0. The comparison of TOF for different systems suggests that cobalt sites surrounded with nitrogen atoms exhibit superior catalytic performance compared to the ones surrounded with oxygen and/or sulfur atoms.

Controlled potential electrolysis (CPE) experiment was performed to calculate faradaic efficiency (Fig. 4a) [16]. The charge measured during electrolysis was used to calculate the theoretical amount of evolved $\mathrm{H}_{2}$ and the amount of evolved $\mathrm{H}_{2}$ gas was detected with gas chromatography. A faradaic efficiency of $\sim 98 \%$ was obtained, which indicates that the only origin of charge accumulated is due to catalytic $\mathrm{H}_{2}$ evolution (Fig. 4b).

\subsection{Electrode Characterization}

Figure 5 represents XPS studies performed on the $\left[\mathrm{CoCo}(\mathrm{CN})_{6} @ \mathrm{FTO}\right]$ before (pristine) and after (post-catalytic) bulk electrolysis at $-0.8 \mathrm{~V}$ (vs. NHE). The Co2p spectrum of pristine Co-Co PBA shows sharp and distinctive principle $\mathrm{Co} 2 \mathrm{p}_{3 / 2}$ and $\mathrm{Co} 2 \mathrm{p}_{1 / 2}$ signals, respectively, at duced with Co-Co PBA versus time confirmed by GC. The quantity of $\mathrm{H}_{2}$ ( $\mu \mathrm{mol}$ ) is integrated from gas chromatography (red spheres) and also from Faraday's Law (black squares)

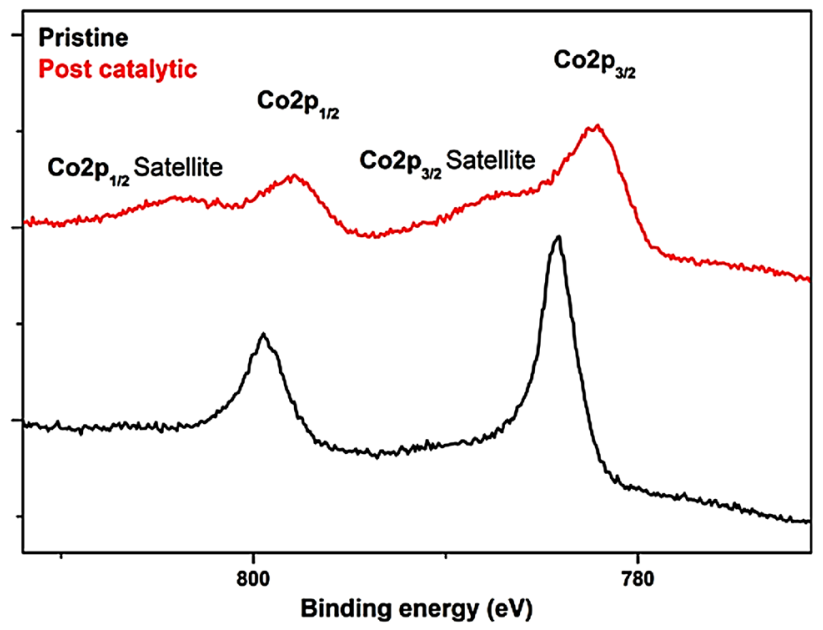

Fig. 5 XPS spectra of Co2p signals of Co-Co PBA

784.38 and $799.48 \mathrm{eV}[34,36,45]$ with scalable FWHM of $\sim 2 \mathrm{eV}$ while the post-catalytic electrode shows broad principle Co2 $\mathrm{p}_{3 / 2}$ and Co2 $\mathrm{p}_{1 / 2}$ signals at 782 and $797.68 \mathrm{eV}$, respectively, with relatively wider FWHM of $\sim 3 \mathrm{eV}$. Furthermore, weak but identifiable satellite signals at 788.38 and $803.98 \mathrm{eV}$ were observed for the post-catalytic electrode corresponding to $\mathrm{Co} 2 \mathrm{p}_{3 / 2}$ and $\mathrm{Co} 2 \mathrm{p}_{1 / 2}$, respectively. The appearance of identifiable satellite signals in the postcatalytic electrode suggests partial reduction of the cobalt sites. GI-XRD (grazing incidence) analysis was also performed on $\left[\mathrm{CoCo}(\mathrm{CN})_{6} @ \mathrm{FTO}\right]$ to investigate the change in crystallinity during electrolysis. No distinguishable change was observed between the pristine and post-catalytic electrodes in the patterns as shown in Fig. 6, which indicates that 


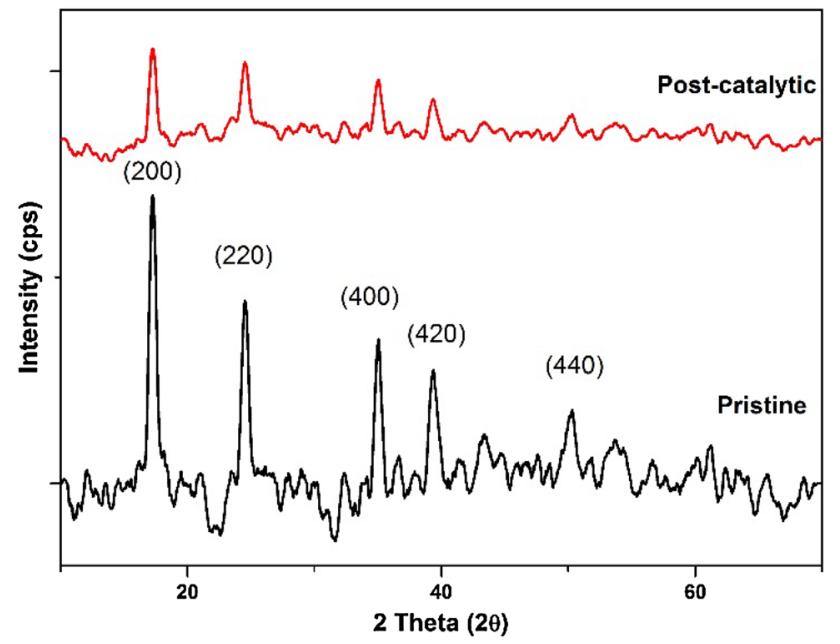

Fig. 6 Thin film XRD for pristine (black) and post-catalytic (red) $\left[\mathrm{CoCo}(\mathrm{CN})_{6} @ \mathrm{FTO}\right]$ electrodes

the structure and the composition of the Co-Co PBA is not affected by the partial reduction of cobalt sites. The stability of Co-Co PBA has also been confirmed by comparisons of SEM images and EDX patterns of pristine and post-catalytic electrodes. From the SEM images (Figs. S4-S5) of pristine and post-catalytic $\left[\mathrm{CoCo}(\mathrm{CN})_{6} @ \mathrm{FTO}\right]$, no distinguishable loss in catalyst surface can be observed, indicating that the catalyst is robust under the conditions subjected for electrochemical measurements. EDX analysis of the pristine \& post-catalytic electrodes reveals a mild hike in the atomic percentage of $\mathrm{K}$, which is attributed to the critical role of potassium ions in providing charge neutrality of the catalyst during water reduction (Table S1). Water reduction involves a mechanism where cobalt sites are reduced to their lower valencies [48], which increases anionic character of the coordination framework. The charge neutrality of the Prussian blue framework is then provided with the insertion of potassium ions available in the solution during such redox processes. The transport of potassium ions is reversible thanks to the microchannels in PB structure and this phenomenon has been observed when PBAs are oxidized under anodic potentials as well [49].

Therefore, it can be assumed that the partial reduction in the cobalt sites is reversible. XPS studies of Co2p and $\mathrm{Zn} 2 \mathrm{p}$ signals of both pristine and post-catalytic $\mathrm{Zn}-\mathrm{Co}$ PBA were given in the Electronic Supporting information (Supporting Fig. S3a and b). The pristine $\mathrm{Zn}-\mathrm{Co}$ PBA shows sharp, distinctive principle Co2 $\mathrm{p}_{3 / 2}$ signal at $786.08 \mathrm{eV}$ and $\mathrm{Co} 2 \mathrm{p}_{1 / 2}$ signal at $801.08 \mathrm{eV}$, with scalable FWHM of $\sim 3.5 \mathrm{eV}$. Where in the post-catalytic $\mathrm{Zn}-\mathrm{Co}$ shows sharp principle Co2 $\mathrm{p}_{3 / 2}$ signal at $784.68 \mathrm{eV}$ and Co2 $p_{1 / 2}$ signal at $799.48 \mathrm{eV}$ with a FWHM of $\sim 3 \mathrm{eV}$. The pristine $\mathrm{Zn}-\mathrm{Co}$ PBA shows sharp, intense principle $\mathrm{Zn} 2 \mathrm{p}_{3 / 2}$ signal at $1025.88 \mathrm{eV}$ and $\mathrm{Zn} 2 \mathrm{p}_{1 / 2}$ signal at
$1048.98 \mathrm{eV}$ with a FWHM of $\sim 3 \mathrm{eV}$. The post-catalytic $\mathrm{Zn}-\mathrm{Co}$ PBA shows broad but intense principle $\mathrm{Zn} 2 \mathrm{p}_{3 / 2}$ signal at $1024.18 \mathrm{eV}$ and $\mathrm{Zn} 2 \mathrm{p}_{1 / 2}$ signal at $1047.08 \mathrm{eV}$ with a FWHM of $\sim 1.8 \mathrm{eV}$. The absence of any additional satellite signals in both Co2p and $\mathrm{Zn} 2 \mathrm{p}$ lines of the $\mathrm{Zn}-\mathrm{Co}$ PBA electrodes confirms that there is no change in the oxidation states suggesting the absence of electrochemical activity.

\section{Conclusions}

PBAs with their unique structural motives wherein metal ions are connected to each other with cyanide groups meet the requirements for an ideal electrocatalyst: easy synthesis, superior robustness in a wide range of $\mathrm{pH}$ and at high cathodic potentials, and being composed of earth abundant elements. Furthermore, Prussian Blue analogues have been studied in the fields of water oxidation and hydrogen peroxide sensing due to their interesting electrochemical properties. Where in this study, demonstrated for the first time that a Co-Co Prussian Blue analogue can be used as an efficient water reduction catalyst as well. Comparative electrochemical studies indicate that catalytic activity of Prussian Blue analogue is due to the cobalt(II) ions surrounded by the nitrogen atoms of nitrile group. $\mathrm{Co}-\mathrm{Co}$ Prussian Blue modified FTO electrode exhibits a significant HER activity with an onset overpotential of $257 \mathrm{mV}$. The Tafel slope obtained from cyclic voltammetry of the electrode $\left(80 \mathrm{mV} \mathrm{sec}{ }^{-1}\right)$ is in good accordance with the previously studied cobalt-based heterogeneous systems, which suggests a mechanism involving the formation of a metal-hydride intermediate followed by reaction of hydride and the proton of water resulting in $\mathrm{H}_{2}$ evolution. The catalyst performs at a much higher turnover frequency $\left(0.090 \mathrm{~s}^{-1}\right.$ at an overpotential $\left.250 \mathrm{mV}\right)$ compared to other cobalt-based systems. Long-term electrolysis studies together with comprehensive characterization studies confirm that the catalyst retains its structure throughout the catalytic process.

The diversity of cyanometalates provides several opportunities to enhance their catalytic activities further; (a) other metal hexacyanomatalates can be prepared to investigate the catalytic activity of other commonly studied $3 \mathrm{~d}$ metal ions such as $\mathrm{Fe}$ and $\mathrm{Ni}$, (b) pentacyanometalate precursors can be used to increase the surface concentration of cobalt sites as was done previously for cyanide-based water oxidation catalysts [50], and (c) composites consisting of PBAs and carbon nanotubes can be prepared. These studies are currently in progress. Since PBAs have recently been reported as efficient water oxidation electrocatalysts and photocatalysts, PBAs could also be used in further studies in both sides of water splitting to build a symmetric electrolytic cell. 
Acknowledgements This work was suppoerted by the Grants from The Science and Technology Council of Turkey, TUBITAK (Project No: 215Z249). E. U. thanks TUBITAK for support (Project No: 1929B011500059).

\section{References}

1. Goldemberg J (1995) Energy needs in developing countries and sustainability. Science 269:1058-1059. https://doi.org/10.1126/ science. 269.5227 .1058

2. Hoel M, Kverndokk S (1996) Depletion of fossil fuels and the impacts of global warming. Resour Energy Econ 18:115-136. https://doi.org/10.1016/0928-7655(96)00005-X

3. Höök M, Tang X (2013) Depletion of fossil fuels and anthropogenic climate change: a review. Energy Policy 52:797-809. https://doi.org/10.1016/j.enpol.2012.10.046

4. Schlapbach L, Züttel A (2001) Hydrogen-storage materials for mobile applications. Nature 414:353-358. https://doi. org $/ 10.1038 / 35104634$

5. Durbin DJ, Malardier-Jugroot C (2013) Review of hydrogen storage techniques for on board vehicle applications. Int $\mathrm{J}$ Hydrog Energy 38:14595-14617. https://doi.org/10.1016/j. ijhydene.2013.07.058

6. Paggiaro R, Bénard P, Polifke W (2010) Cryo-adsorptive hydrogen storage on activated carbon I: thermodynamic analysis of adsorption vessels and comparison with liquid and compressed gas hydrogen storage. Int J Hydrog Energy 35:638-647. https:// doi.org/10.1016/j.ijhydene.2009.10.108

7. Weinberger B, Lamari FD (2009) High pressure cryo-storage of hydrogen by adsorption at $77 \mathrm{~K}$ and up to $50 \mathrm{MPa}$. Int J Hydrog Energy 34:3058-3064. https://doi.org/10.1016/j. ijhydene.2009.01.093

8. Ahluwalia RK, Hua TQ, Peng J-K, Lasher S, McKenney K, Sinha J et al (2010) Technical assessment of cryo-compressed hydrogen storage tank systems for automotive applications. Int J Hydrog Energy 35:4171-4184. https://doi.org/10.1016/j. ijhydene.2010.02.074

9. Wang L, Zheng C, Li R, Chen B, Wei Z (2014) Numerical analysis of temperature rise within $70 \mathrm{MPa}$ composite hydrogen vehicle cylinder during fast refueling. J Cent South Univ 21:2772-2778. https://doi.org/10.1007/s11771-014-2240-9

10. Khan MTI, Monde M, Setoguchi T (2009) Hydrogen gas filling into an actual tank at high pressure and optimization of its thermal characteristics. J Therm Sci 18:235-240. https://doi.org/10.1007/ s11630-009-0235-x

11. Koper MTM, Bouwman E (2010) Electrochemical hydrogen production: bridging homogeneous and heterogeneous catalysis. Angew Chem Int Ed 49:3723-3725. https://doi.org/10.1002/ anie. 201000629

12. Parsons R (1958) The rate of electrolytic hydrogen evolution and the heat of adsorption of hydrogen. Trans Faraday Soc 54:10531063. https://doi.org/10.1039/tf9585401053

13. Burke LD, Naser NS, Ahern BM (2007) Use of iridium oxide films as hydrogen gas evolution cathodes in aqueous media. $\mathrm{J}$ Solid State Electrochem 11:655-666. https://doi.org/10.1007/ s10008-006-0221-0

14. Durst J, Simon C, Hasche F, Gasteiger HA (2014) Hydrogen oxidation and evolution reaction kinetics on carbon supported Pt, Ir, $\mathrm{Rh}$, and Pd electrocatalysts in acidic media. J Electrochem Soc 162:F190-F203. https://doi.org/10.1149/2.0981501jes

15. Sheng W, Gasteiger HA, Shao-Horn Y (2010) Hydrogen oxidation and evolution reaction kinetics on platinum: acid vs alkaline electrolytes. J Electrochem Soc 157:B1529-B1536. https://doi. org/10.1149/1.3483106
16. Rioual S, Lescop B, Quentel F, Gloaguen F (2015) A molecular material based on electropolymerized cobalt macrocycles for electrocatalytic hydrogen evolution. Phys Chem Chem Phys 17:13374-13379. https://doi.org/10.1039/C5CP01210D

17. Gloaguen F, Rauchfuss TB (2009) Small molecule mimics of hydrogenases: hydrides and redox. Chem Soc Rev 38:100-108. https://doi.org/10.1039/B801796B

18. Wang M, Chen L, Sun L (2012) Recent progress in electrochemical hydrogen production with earth-abundant metal complexes as catalysts. Energy Environ Sci 5:6763-6778. https://doi. org/10.1039/c2ee03309g

19. Thoi VS, Sun Y, Long JR, Chang CJ (2013) Complexes of earthabundant metals for catalytic electrochemical hydrogen generation under aqueous conditions. Chem Soc Rev 42:2388-2400. https:// doi.org/10.1039/C2CS35272A

20. Losse S, Vos JG, Rau S (2010) Catalytic hydrogen production at cobalt centres. Coord Chem Rev 254:2492-2504. https://doi. org/10.1016/j.ccr.2010.06.004

21. Artero V, Chavarot-Kerlidou M, Fontecave M (2011) Splitting water with cobalt. Angew Chem Int Ed 50:7238-7266. https:// doi.org/10.1002/anie.201007987

22. Wiedner ES, Bullock RM (2016) Electrochemical detection of transient cobalt hydride intermediates of electrocatalytic hydrogen production. J Am Chem Soc 138:8309-8318. https://doi. org/10.1021/jacs.6b04779

23. Lo WKC, Castillo CE, Gueret R, Fortage J, Rebarz M, Sliwa $M$ et al (2016) Synthesis, characterization, and photocatalytic $\mathrm{H}_{2}$-evolving activity of a family of $[\mathrm{Co}(\mathrm{N} 4 \mathrm{Py})(\mathrm{X})]^{n+}$ complexes in aqueous solution. Inorg Chem 55:4564-4581. https://doi. org/10.1021/acs.inorgchem.6b00391

24. Kandemir B, Kubie L, Guo Y, Sheldon B, Bren KL (2016) Hydrogen evolution from water under aerobic conditions catalyzed by a cobalt ATCUN metallopeptide. Inorg Chem 55:1355-1357. https://doi.org/10.1021/acs.inorgchem.5b02157

25. Sun Y, Bigi JP, Piro NA, Tang ML, Long JR, Chang CJ (2011) Molecular cobalt pentapyridine catalysts for generating hydrogen from water. J Am Chem Soc 133:9212-9215. https://doi. org $/ 10.1021 / \mathrm{ja} 202743 \mathrm{r}$

26. Cobo S, Heidkamp J, Jacques P-A, Fize J, Fourmond V, Guetaz L et al (2012) A janus cobalt-based catalytic material for electrosplitting of water. Nat Mater 11:802-807. https://doi.org/10.1038/ nmat3385

27. Sun Y, Liu C, Grauer DC, Yano J, Long JR, Yang P et al (2013) Electrodeposited cobalt-sulfide catalyst for electrochemical and photoelectrochemical hydrogen generation from water. J Am Chem Soc 135:17699-17702. https://doi.org/10.1021/ja4094764

28. Khnayzer RS, Thoi VS, Nippe M, King AE, Jurss JW, El Roz KA et al (2014) Towards a comprehensive understanding of visiblelight photogeneration of hydrogen from water using cobalt(ii) polypyridyl catalysts. Energy Environ Sci 7:1477-1488. https:// doi.org/10.1039/c3ee43982h

29. Kaye SS, Long JR (2005) Hydrogen storage in the dehydrated prussian blue analogues $\mathrm{M}_{3}\left[\mathrm{Co}(\mathrm{CN})_{6}\right]_{2}(\mathrm{M}=\mathrm{Mn}, \mathrm{Fe}, \mathrm{Co}, \mathrm{Ni}, \mathrm{Cu}$, Zn). J Am Chem Soc 127:6506-6507. https://doi.org/10.1021/ ja051168t

30. Hartman MR, Peterson VK, Liu Y, Kaye SS, Long JR (2006) Neutron diffraction and neutron vibrational spectroscopy studies of hydrogen adsorption in the prussian blue analogue $\mathrm{Cu}_{3}\left[\mathrm{Co}(\mathrm{CN})_{6}\right]_{2}$. Chem Mater 18:3221-3224. https://doi. org/10.1021/cm0608600

31. Tian J, Liu Q, Asiri AM, Sun X (2014) Self-supported nanoporous cobalt phosphide nanowire arrays: an efficient 3D hydrogenevolving cathode over the wide range of $\mathrm{pH} 0-14$. J Am Chem Soc 136:7587-7590. https://doi.org/10.1021/ja503372r

32. Yamada Y, Oyama K, Gates R, Fukuzumi S (2015) High catalytic activity of heteropolynuclear cyanide complexes containing cobalt 
and platinum ions: visible-light driven water oxidation. Angew Chem 127:5705-5709. https://doi.org/10.1002/ange.201501116

33. Abe T, Taguchi F, Tokita S, Kaneko M (1997) Prussian White as a highly active molecular catalyst for proton reduction. J Mol Catal A Chem 126:L89-L92. https://doi.org/10.1016/ S1381-1169(97)00156-8

34. Pintado S, Goberna-Ferrón S, Escudero-Adán EC, Galán-Mascarós JR (2013) Fast and persistent electrocatalytic water oxidation by Co-Fe prussian blue coordination polymers. J Am Chem Soc 135:13270-13273. https://doi.org/10.1021/ja406242y

35 Roque J, Reguera E, Balmaseda J, Rodríguez-Hernández J, Reguera L, del Castillo LF (2007) Porous hexacyanocobaltates(III): role of the metal on the framework properties. Micropor Mesopor Mat 103(1-3):57-71

36. Goberna-Ferrón S, Hernández WY, Rodríguez-García B, GalánMascarós JR (2014) Light-driven water oxidation with metal hexacyanometallate heterogeneous catalysts. ACS Catal 4:16371641. https://doi.org/10.1021/cs500298e

37. Jin Z, Li P, Huang X, Zeng G, Jin Y, Zhenga B, Xiao D (2014) Three-dimensional amorphous tungsten-doped nickel phosphide microsphere as an efficient electrocatalyst for hydrogen evolution. J Mater Chem A 2:18593-18599. https://doi.org/10.1039/ c4ta04434g

38. Gupta S, Patel N, Fernandes R, Kadrekar R, Dashora A, Yadav AK et al (2016) Co-Ni-B nanocatalyst for efficient hydrogen evolution reaction in wide $\mathrm{pH}$ range. Appl Catal B 192:126-133. https://doi.org/10.1016/j.apcatb.2016.03.032

39. Tian J, Liu Q, Liang Y, Xing Z, Asiri AM, Sun X (2014) FeP nanoparticles film grown on carbon cloth: an ultrahighly active 3D hydrogen evolution cathode in both acidic and neutral solutions. ACS Appl Mater Interfaces 6:20579-20584. https://doi. org/10.1021/am5064684

40. Peng Z, Jia D, Al-Enizi AM, Elzatahry AA, Zheng G (2015) Electrocatalysts: from water oxidation to reduction: homologous $\mathrm{Ni}-\mathrm{Co}$ based nanowires as complementary water splitting electrocatalysts (Adv. Energy Mater. 9/2015). Adv Energy Mater 5:1402031-1402037. https://doi.org/10.1002/aenm.201570050

41. Pu Z, Liu Q, Jiang P, Asiri AM, Obaid AY, Sun X (2014) CoP nanosheet arrays supported on a Ti plate: an efficient cathode for electrochemical hydrogen evolution. Chem Mater 26:4326-4329. https://doi.org/10.1021/cm501273s

42. Gupta S, Patel N, Miotello A, Kothari DC (2015) Cobalt-boride: an efficient and robust electrocatalyst for hydrogen evolution reaction. J Power Sources 279:620-625. https://doi.org/10.1016/j. jpowsour.2015.01.009

43. Pan Y, Lin Y, Chen Y, Liu Y, Liu C (2016) Cobalt phosphidebased electrocatalysts: synthesis and phase catalytic activity comparison for hydrogen evolution. J Mater Chem A 4:4745-4754. https://doi.org/10.1039/C6TA00575F

44. Tilak BV, Chen C-P (1993) Generalized analytical expressions for Tafel slope, reaction order and a.c. impedance for the hydrogen evolution reaction (HER): mechanism of HER on platinum in alkaline media. J Appl Electrochem 23:631-640

45. Conway BE, Jerkiewicz G (1993) Thermodynamic and electrode kinetic factors in cathodic hydrogen sorption into metals and its relationship to hydrogen adsorption and poisoning. J Electroanal Chem 357:47-66. https://doi.org/10.1016/0022-0728(93)80373-P

46. Kong D, Wang H, Lu Z, Cui Y (2014) $\mathrm{CoSe}_{2}$ nanoparticles grown on carbon fiber paper: an efficient and stable electrocatalyst for hydrogen evolution reaction. J Am Chem Soc 136:4897-4900. https://doi.org/10.1021/ja501497n

47. Chen Z, Cummins D, Reinecke BN, Clark E, Sunkara MK, Jaramillo TF (2011) Core-shell $\mathrm{MoO}_{3}-\mathrm{MoS}_{2}$ nanowires for hydrogen evolution: a functional design for electrocatalytic materials. Nano Lett 11:4168-4175. https://doi.org/10.1021/n12020476

48. McKone JR, Marinescu SC, Brunschwig BS, Winkler JR, Gray HB (2014) Earth-abundant hydrogen evolution electrocatalysts. Chem Sci 5:865-878

49. Alsaç EP, Ülker E, Nune SVK, Dede Y, Karadas F Tuning electronic properties of prussian blue analogues for efficient water oxidation electrocatalysis: experimental and computational studies. Chem Eur J. https://doi.org/10.1002/chem.201704933

50. Aksoy M, Nune SVK, Karadas F (2016) A novel synthetic route for the preparation of an amorphous $\mathrm{Co} / \mathrm{Fe}$ prussian blue coordination compound with high electrocatalytic water oxidation activity. Inorg Chem 55:4301-4307. https://doi.org/10.1021/acs. inorgchem.6b00032 